\title{
Incidence, outcome, and attributable resource use associated with pulmonary and cardiac complications after major small and large bowel procedures
}

\author{
Lee A Fleisher ${ }^{1 *}$ and Walter T Linde-Zwirble ${ }^{2}$
}

\begin{abstract}
Background: Complications increase the costs of care of surgical patients. We studied the Premier database to determine the incidence and direct medical costs related to pulmonary complications and compared it to cardiac complications in the same cohort.

Methods: We identified 45,969 discharges in patients undergoing major bowel procedures. Postoperative pulmonary and cardiac complications were identified through the use of International Classification of Diseases, Ninth Edition, Clinical Modification (ICD-9-CM) codes and through the use of daily resource use data. Pulmonary complications included pneumonia, tracheobronchitis, pleural effusion, pulmonary failure, and mechanical ventilation more than $48 \mathrm{~h}$ after surgery. Cardiac complications included ventricular fibrillation, acute myocardial infarction, cardiogenic shock, cardiopulmonary arrest, transient ischemia, premature ventricular contraction, and acute congestive heart failure.

Results: Postoperative pulmonary complications (PPC) or postoperative cardiac complications (PCC) were present in 22\% of cases; PPC alone was most common (19.0\%), followed by PPC and PCC (1.8\%) and PCC alone (1.2\%). The incremental cost of PPC is large $(\$ 25,498)$. In comparison, PCC alone only added $\$ 7,307$ to the total cost.

Conclusions: The current study demonstrates that postoperative pulmonary complications represent a significant source of morbidity and incremental cost after major small intestinal and colon surgery and have greater incidence and costs than cardiac complications alone. Therefore, strategies to reduce the incidence of these complications should be targeted as means of improving health and bending the cost curve in health care.
\end{abstract}

Keywords: Colectomy, Surgery, Postoperative, Pulmonary complications, Myocardial infarction, Cardiac arrest, Pneumonia, Cost

\section{Background}

During the past decade, there has been a marked decrease in surgical mortality [1]. This decrease appears to be related in part to better treatment of complications in some hospitals since perioperative complications remain high and continue to be a significant source of both decreased health and increased costs after surgery [2].

\footnotetext{
* Correspondence: lee.fleisher@uphs.upenn.edu

'Department of Anesthesiology and Critical Care, Perelman School of Medicine, Leonard Davis Institute of Health Economics, University of Pennsylvania, 3400 Spruce Street, Dulles 680, Philadelphia, PA 19104, USA Full list of author information is available at the end of the article
}

Beginning in the 1970s, there was a concerted effort to identify patients at increased risk of perioperative cardiovascular morbidity and mortality and to identify strategies to reduce these complications. This has led to the development and publication of formal Guidelines on Perioperative Cardiovascular Evaluation and Management for Noncardiac Surgery and incorporation of specific therapies into public performance measurement [3]. In contrast to cardiovascular disease, the evaluation and management of perioperative pulmonary complications has not had the same degree of concerted effort to either identify those at risk or implement additional risk reduction strategies. 
The absence of a concerted focus on perioperative pulmonary complications may in part be due to the lack of recognition of their incidence and their economic burden [4]. An additional issue is related to the definition of pulmonary complications since there is wide variability in manifestations of complications: from minor aspiration to pneumonia to overt sepsis. Assessing the impact of pulmonary complications is also difficult since a pulmonary complication may lead to cardiovascular collapse with resultant cardiac morbidity or mortality. Pulmonary complications may also be the final common pathway for major morbidity or mortality in patients with other complications such as non-pulmonary infectious complications. Given the lack of concerted attention in this important area of health-care outcomes, we analyzed an enriched administrative dataset to determine the incidence and direct medical costs related to pulmonary complications in order to provide more focused attention on the problem and provide an impetus to identify cost-effective risk-reducing strategies and compared it to cardiac complications in the same cohort.

\section{Methods}

\section{Case selection}

We constructed the study cohort using the 2008 Premier Hospital Discharge database. The Premier database (Premier, Inc., Charlotte, NC, USA) includes information on all inpatients and hospital-based outpatients treated in more than 600 US hospitals. The database includes patient demographic data and diagnosis codes; the date-stamped $\log$ of all invoiced items, including procedures, medications, laboratory orders, diagnostic, and therapeutic services; as well as devices used by individual patients. The cohort of interest consisted of all discharges, age 18 years and older, in the Medicare Severity DRGs 329-331, major small and large bowel procedures. For each case, we extracted the following: demographic characteristics; principal diagnosis group (neoplasm, colitis/diverticulitis, other); Charlson-Deyo co-morbidities; postoperative pulmonary and cardiac complications; postoperative length of stay (LOS); postoperative intensive care unit (ICU) use; postoperative ICU LOS; total hospital costs; and national projection weights.

\section{Identification of postoperative complications}

Postoperative pulmonary and cardiac complications were identified through the use of International Classification of Diseases, Ninth Edition, Clinical Modification (ICD-9$\mathrm{CM}$ ) codes in any secondary coding space and through the use of daily resource use data. Pulmonary complications included pneumonia $(481,482,485,486)$; tracheobronchitis (494.1, 466, 464.1); pleural effusion (511.1, 511.8, 511.9); pulmonary failure (518.81, 518.84); and mechanical ventilation more than $48 \mathrm{~h}$ after surgery (from daily resource use). Cardiac complications included ventricular fibrillation (427.4); acute myocardial infarction (410.X1); cardiogenic shock (785.51); cardiopulmonary arrest (427.5); transient ischemia (411.1, 411.89); premature ventricular contraction (PVC) (427.6); and acute congestive heart failure $(428.21,428.31,428.41)$.

\section{Case-mix adjustment}

We constructed a case-mix adjustment model to characterize the impact of preoperative characteristics on the incidence of postoperative complications and estimate the attributable effects of PPC and PCC on resource use and outcome. We constructed an analysis of variance model using patients with no PPC and no PCC to predict total cost as a function of age group; principal diagnosis group (neoplasm-150-59, 183, 188, 195, 197, 209, 211, 214, 228, 230-35, 239; colitis/diverticulitis-555-569; and other); and Charlson-Deyo co-morbidity. We chose cost and not mortality risk as a severity measure because hospital mortality is very low in those without postoperative complications. The predicted cost equation was applied to all cases, both those with and without postoperative complications, and subjects were characterized by quintiles of preoperative severity.

\section{Resource use and outcome presentation}

Overall mortality and resource use was presented directly and also parsed into a base value, what was expected had there been no postoperative complications, and an incremental effect, the difference between the total and base values.

\section{Statistical analysis}

We compared continuous data using the Mann-Whitney $U$ test and categorical data by chi-squared or Fisher's exact test as appropriate. We organized patient data by the presence of postoperative complications (PPC only, PCC only, neither PPC nor PCC, and both PPC and PCC) and by quintiles $(\mathrm{Q})$ of preoperative severity. We generated national estimates using Premier-supplied weights. We constructed the databases in FoxPro (Microsoft Corp, Redmond, WA, USA) and conducted analyses in Data Desk (Data Description, Ithaca, NY, USA).

\section{Results}

We identified 45,969 discharges with major small and large bowel procedures. The average age was 62.9 years and $45.1 \%$ were male. Descriptive characteristics are provided in Table 1. Colitis/diverticulitis was the most common principal diagnosis (43.7\%), followed by neoplasm (39.3\%) and other (17.0\%). More than a third of the cohort (37.2\%) had at least one Charlson-Deyo co-morbidity, with diabetes being the most common (15.8\%) followed 
Table 1 Major small and large bowel procedure cohort characteristic, overall and by postoperative complication group

\begin{tabular}{|c|c|c|c|c|c|}
\hline Variables & $\begin{array}{c}\text { All } \\
(n=45,969)\end{array}$ & $\begin{array}{l}\text { No PPC/PCC } \\
(n=35,875)\end{array}$ & $\begin{array}{l}\text { PPC alone } \\
(n=8,744)\end{array}$ & $\begin{array}{l}\text { PCC alone } \\
(n=547)\end{array}$ & $\begin{array}{c}\text { PPC and PCC } \\
(n=803)\end{array}$ \\
\hline Rate (\%) & & 78.0 & 19.0 & 1.2 & 1.8 \\
\hline Hospital mortality (\%) & 3.6 & 0.7 & 11.9 & 12.6 & 36.1 \\
\hline Age (mean, years) & 62.9 & 61.3 & 67.8 & 73.7 & 74.5 \\
\hline \multicolumn{6}{|l|}{ Age group (\%) } \\
\hline $18-34$ & 5.4 & 6.2 & 3.2 & 0.9 & 0.6 \\
\hline $35-54$ & 23.8 & 26.5 & 15.6 & 6.2 & 5.7 \\
\hline $55-64$ & 21.3 & 22.3 & 18.5 & 14.3 & 10.8 \\
\hline $65-74$ & 22.2 & 21.7 & 23.7 & 23.9 & 25.7 \\
\hline $75-84$ & 19.7 & 17.6 & 26.0 & 35.8 & 37.0 \\
\hline $85+$ & 7.5 & 5.8 & 12.9 & 18.8 & 20.2 \\
\hline Sex, male (\%) & 45.1 & 45.0 & 45.3 & 49.2 & 46.8 \\
\hline \multicolumn{6}{|l|}{ Race (\%) } \\
\hline White & 70.2 & 70.2 & 69.7 & 72.4 & 71.5 \\
\hline Black & 10.4 & 10.0 & 12.0 & 11.2 & 12.0 \\
\hline Other & 19.4 & 19.8 & 18.3 & 16.5 & 16.6 \\
\hline \multicolumn{6}{|l|}{ Charlson-Deyo co-morbidity (\%) } \\
\hline Diabetes & 15.8 & 14.6 & 19.9 & 22.7 & 24.7 \\
\hline Complicated diabetes & 1.4 & 1.1 & 2.3 & 2.2 & 3.1 \\
\hline Chronic pulmonary disease & 8.0 & 5.9 & 16.0 & 12.6 & 16.6 \\
\hline Chronic renal disease & 6.4 & 4.4 & 12.9 & 14.1 & 21.2 \\
\hline Neoplasm & 5.7 & 5.0 & 8.5 & 5.3 & 7.2 \\
\hline Metastatic neoplasm & 13.1 & 12.6 & 14.6 & 14.6 & 14.1 \\
\hline Cerebrovascular disease & 1.1 & 0.9 & 1.9 & 1.5 & 2.7 \\
\hline Dementia & 0.3 & 0.2 & 0.6 & 1.1 & 0.6 \\
\hline Prior myocardial infarction & 4.0 & 3.5 & 5.0 & 11.5 & 10.5 \\
\hline Para- and quadriplegia & 0.4 & 0.3 & 0.9 & 0.9 & 1.4 \\
\hline Peripheral vascular disease & 3.1 & 2.3 & 5.5 & 9.9 & 9.2 \\
\hline Chronic rheumatic disease & 2.2 & 1.9 & 3.2 & 2.5 & 3.2 \\
\hline Mild liver disease & 0.9 & 0.7 & 1.7 & 1.1 & 1.7 \\
\hline Severe liver disease & 0.4 & 0.2 & 1.1 & 0.4 & 1.2 \\
\hline HIV & 0.1 & 0.1 & 0.1 & 0.0 & 0.0 \\
\hline Any co-morbidity & 37.2 & 34.1 & 47.2 & 53.2 & 55.8 \\
\hline Mean number & 0.6 & 0.5 & 0.9 & 1.0 & 1.2 \\
\hline
\end{tabular}

by metastatic neoplasm (13.1\%) and chronic pulmonary conditions (8.0\%).

\section{Incidence and survival}

Pulmonary or cardiac complications were present in $22 \%$ of cases; PPC alone was most common (19.0\%), followed by PPC and PCC (1.8\%) and PCC alone (1.2\%). Those with postoperative complications were older and had a greater co-morbid burden than those that did not.

Those with PPC alone had 11.9\% mortality and accounted for nearly two thirds (63.6\%) of hospital deaths (Figure 1).
PCC alone cases had a similar mortality (12.6\%) but accounted for only $4.2 \%$ of deaths. Those with PPC and PCC had the highest mortality (36.1\%), though only $1.3 \%$ of the cohort accounted for $17.7 \%$ of deaths.

\section{Individual complications}

Respiratory failure was the most common postoperative complication, being present in one in eight patients with $21.8 \%$ mortality (Table 2). Other pulmonary complications ranged from $0.4 \%$ incidence (pneumothorax) to $6.1 \%$ (MV48). Overall, 20.8\% of patients had at least one 


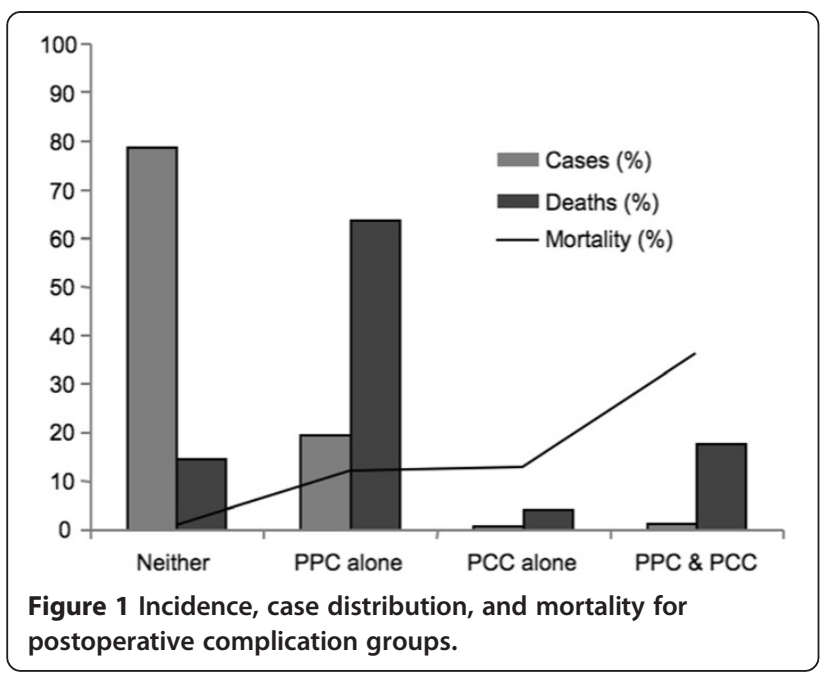

PPC with a combined hospital mortality of $13.9 \%$. Cardiac complications (2.9\% incidence) were seven times less frequent than pulmonary complications, but with higher hospital mortality (26.6\%). Acute myocardial infarction (AMI) was the most common PCC but occurred in only $1.2 \%$ of patients.

\section{Severity model}

The average cost of those without PPC and PCC increased with age $(\$ 2,732$ more for those over 85 compared to

Table 2 Incidence and hospital mortality for postoperative complications

\begin{tabular}{lccc}
\hline Complications & $\begin{array}{c}\text { Cases } \\
\text { (\% of group) }\end{array}$ & Rate (\%) & Mortality (\%) \\
\hline Pulmonary & & & \\
Pneumonia & $2,249(23.6)$ & 4.9 & 14.4 \\
Tracheobronchitis & $434(4.5)$ & 0.9 & 6.2 \\
Pleural effusion & $1,584(16.6)$ & 3.4 & 13.7 \\
Pulmonary collapse & $3,499(36.7)$ & 7.6 & 6.2 \\
Pneumothorax & $189(2.0)$ & 2.0 & 24.9 \\
Respiratory failure & $5,686(59.6)$ & 12.4 & 21.8 \\
MV48 & $2,807(29.4)$ & 6.1 & 28.5 \\
Any pulmonary & 9,547 & 20.8 & 13.9 \\
Cardiac & & 0.8 & 26.6 \\
Ventricular fibrillation & $63(4.7)$ & 0.1 & 6.9 \\
AMl & $570(42.2)$ & 1.2 & 26.7 \\
Cardiogenic shock & $64(4.7)$ & 0.1 & 57.8 \\
Cardiopulmonary arrest & $220(16.3)$ & 0.5 & 70.9 \\
Transient ischemia & $47(3.5)$ & 0.1 & 2.9 \\
PVC & $367(27.2)$ & 0.8 & \\
Acute CHF & $175(13.0)$ & 0.4 & \\
Any cardiac & 1,350 & 2.9 & \\
\hline
\end{tabular}

${ }^{\mathrm{a}}$ Mechanical ventilation more than $48 \mathrm{~h}$ after surgery. those under 35), principal diagnosis of colitis/diverticulitis (\$2,487 more than neoplasm), and co-morbidity (diabetes $\$ 1,091$; peripheral vascular disease $\$ 1,493$; cerebrovascular disease $\$ 4,792$; chronic pulmonary disease $\$ 1,044$; rheumatic disease $\$ 1,544$; complex diabetes $\$ 2,700$; para- and quadriplegia $\$ 3,422$; chronic renal disease $\$ 6,046$; and severe liver disease $\$ 8,706)$. The rate of postoperative complications increased greatly across the quintiles of severity (Table 3), increasing from $11.0 \%$ in the first quintile to $41.7 \%$ in the fifth quintile. While PPC alone tripled from $10.5 \%$ in Q1 to $34.7 \%$ in Q5, the rate of PCC alone and PPC and PCC increased by more than a factor of ten from Q1 to Q5.

\section{Hospital mortality and resource use by severity quintiles}

The base mortality increased from $0.1 \%$ in Q1 to $2.2 \%$ in Q5 for an overall value of $0.7 \%$ (Table 3). This is dwarfed by the incremental mortality associated with PPC alone (11.2\% absolute), PCC alone (12.0\%), and PPC and PCC (35.5\%) (Figure 2). While the base cost increased by $\$ 5,909$ between Q1 and Q5, the incremental cost of PPC is large $(\$ 25,498)$ but increased only modestly from $\$ 22,199$ in Q1 to \$26,508 in Q5 (Figure 3). In comparison, PCC alone only added $\$ 7,307$ to the total cost. Overall, the incremental cost of PPC is $153 \%$ of the mean base cost.

In contrast to mortality and cost, the base ICU use rate increased greatly from 6.0\% in Q1 to $23.3 \%$ in Q5. Those with postoperative complications had much greater ICU use. Postoperative ICU use for those with PPC rose from $48 \%$ in Q1 to 76\% in Q5. This is much greater than PCC alone and less than PPC and PCC, which in Q5 had an ICU use rate of $83.2 \%$. Base postoperative floor LOS ranged from 5.9 days in Q1 to 7.6 days in Q5 with a mean of 6.4 days. PPC alone added 3.5 days, greater than PCC alone (1.3 days) and PPC and PCC (2.8 days). Base postoperative ICU LOS was modest varying only from 0.2 days in Q1 to 0.7 in Q5. The incremental postoperative ICU LOS varied little by preoperative severity but could be large: adding 1.1 ICU days for PCC, 4.5 ICU days for PPC, and 7.1 ICU days for those with PPC and PCC.

\section{National projections}

Projecting to US national levels, there were 308,798 major small and large bowel procedure discharges in 2008, with 59,980 with PPC alone, 3,739 with PCC alone, and 5,295 with PPC and PCC. The expected number of hospital deaths in the absence of PPC and PCC was 2,370 , only $21 \%$ of the observed 11,157 deaths. The expected cost in the absence of postoperative complications was $\$ 5.25 B, 75 \%$ of the observed $\$ 6.99 B$. Similarly, in the absence of PPC and PCC, we would have expected $51.5 \%$ of the observed ICU use, $90 \%$ of postoperative floor days, and $25 \%$ of ICU days to have been used. In summary, PCC alone was associated with $3.8 \%$ of 
Table 3 Association between preoperative severity, postoperative complications, and outcomes

\begin{tabular}{|c|c|c|c|c|c|c|}
\hline Severity quintiles & $\begin{array}{c}\text { Q1 } \\
(n=8,403)\end{array}$ & $\begin{array}{c}\text { Q2 } \\
(n=9,976)\end{array}$ & $\begin{array}{c}\text { Q3 } \\
(n=8,846)\end{array}$ & $\begin{array}{c}\text { Q4 } \\
(n=9,174)\end{array}$ & $\begin{array}{c}\text { Q5 } \\
(n=9,574)\end{array}$ & $\begin{array}{c}\text { Total } \\
(n=45,969)\end{array}$ \\
\hline \multicolumn{7}{|l|}{ Complication rate (\%) } \\
\hline PPC alone & 10.5 & 14.5 & 13.9 & 20.3 & 34.7 & 19.0 \\
\hline PCC alone & 0.2 & 1.3 & 0.8 & 1.3 & 2.2 & 1.2 \\
\hline PPC and PCC & 0.3 & 1.1 & 1.0 & 1.4 & 4.7 & 1.7 \\
\hline Any complication & 11.0 & 16.9 & 15.7 & 23.0 & 41.7 & 21.9 \\
\hline Base mortality (\%) & 0.1 & 0.4 & 0.3 & 0.7 & 2.2 & 0.7 \\
\hline \multicolumn{7}{|l|}{ Incremental mortality (\%) } \\
\hline PPC alone & 5.2 & 7.9 & 8.3 & 8.5 & 15.8 & 11.2 \\
\hline PCC alone & 3.1 & 7.5 & 6.4 & 8.7 & 15.6 & 12.0 \\
\hline PPC and PCC & 13.5 & 35.0 & 33.8 & 32.9 & 36.3 & 35.5 \\
\hline Base cost (\$) & 14,875 & 15,438 & 16,017 & 17,462 & 20,784 & 16,672 \\
\hline \multicolumn{7}{|l|}{ Incremental cost (\$) } \\
\hline PPC alone & 22,199 & 24,199 & 24,658 & 26,817 & 26,508 & 25,498 \\
\hline PCC alone & 5,524 & 5,528 & 9,070 & 4,057 & 9,765 & 7,307 \\
\hline PPC and PCC & 45,308 & 48,950 & 38,096 & 30,884 & 31,394 & 34,872 \\
\hline Base ICU use (\%) & 6.0 & 9.0 & 8.2 & 11.8 & 23.3 & 11.0 \\
\hline \multicolumn{7}{|l|}{ Incremental ICU use (\%) } \\
\hline PPC alone & 42.0 & 45.7 & 50.2 & 54.0 & 52.7 & 54.0 \\
\hline PCC alone & 9.8 & 24.9 & 33.1 & 20.4 & 25.2 & 28.5 \\
\hline PPC and PCC & 71.2 & 67.1 & 75.3 & 68.3 & 59.9 & 70.6 \\
\hline Base post-op ICU LOS (days) & 0.2 & 0.2 & 0.2 & 0.3 & 0.7 & 0.3 \\
\hline \multicolumn{7}{|c|}{ Incremental post-op ICU LOS (days) } \\
\hline PPC alone & 3.0 & 4.0 & 3.7 & 4.6 & 5.0 & 4.5 \\
\hline PCC alone & 0.4 & 0.7 & 1.0 & 0.6 & 1.4 & 1.1 \\
\hline PPC and PCC & 7.5 & 8.0 & 7.5 & 6.7 & 6.5 & 7.1 \\
\hline Base post-op floor LOS (days) & 5.9 & 6.3 & 6.4 & 6.6 & 7.6 & 6.5 \\
\hline \multicolumn{7}{|c|}{ Incremental post-op floor LOS (days) } \\
\hline PPC alone & 3.0 & 4.0 & 3.7 & 4.6 & 5.0 & 4.5 \\
\hline PCC alone & 0.4 & 0.7 & 1.0 & 0.6 & 1.4 & 1.1 \\
\hline $\mathrm{PPC}$ and $\mathrm{PCC}$ & 7.5 & 8.0 & 7.5 & 6.7 & 6.5 & 7.1 \\
\hline
\end{tabular}

deaths, PPC and PCC with $16.4 \%$ of deaths, and PPC alone with $58.5 \%$ of all deaths.

\section{Discussion}

The current study demonstrates that postoperative pulmonary complications represent a significant source of morbidity and incremental cost after major small intestinal and colon surgery and have greater incidence and costs than cardiac complications alone. Although PPC alone was associated with a high incidence of mortality (11.9\%), the combination of PPC and PCC together was associated with the greatest risk. The incidence increased with increasing age until 85 years of age, with over $20 \%$ of all patients experiencing some form of pulmonary complication.
The high incidence of pulmonary complications is consistent with studies utilizing the American College of Surgeons National Surgical Quality Improvement Program (ACS NSQIP), although the actual rate is higher than that in their selected population of hospitals [5]. This may reflect differences in the definition of PPC we used, which included a larger group of diagnoses, or it may reflect differences between hospitals enrolled in a quality improvement program compared to a more random sample. Importantly, we observed a $4.9 \%$ incidence of postoperative pneumonia and $6.1 \%$ incidence of mechanic ventilation greater than $24 \mathrm{~h}$, which is consistent with other studies. For example, Kennedy and colleagues reported a $25.4 \%$ incidence of complications for surgery for 


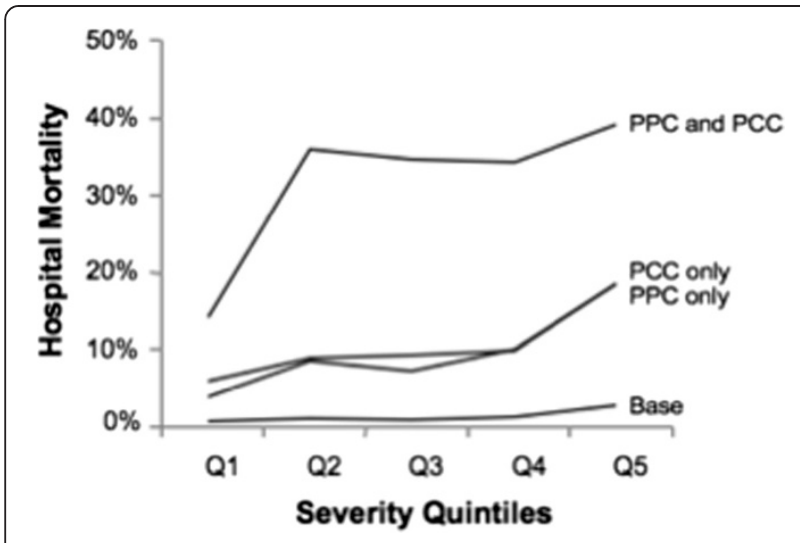

Figure 2 Base and incremental mortalities for postoperative complication groups by preoperative severity groups.

colon cancer, with respiratory complications being the second most common complication after superficial site infection [6]. In contrast, Arozullah and colleagues observed a $1.5 \%$ incidence of postoperative pneumonia in a mixed group of major noncardiac surgery at 100 Veterans Administration Medical Centers [7]. The lower incidence of pneumonia in this population may reflect the type of surgery compared to a cohort of major abdominal surgery in our study.

We observed a high mortality associated with PPC, particularly those with concomitant PCC. Arozullah and colleagues observed a $21 \%$ incidence of 30 -day mortality in those patients with pneumonia compared to our $14.4 \%$ incidence of in-hospital mortality. Jencks and colleagues demonstrated that patients with postoperative pneumonia have a high incidence of readmission, and therefore, our in-hospital mortality rate may not reflect the true 30-day incident [8]. Additionally, we observed a more contemporary cohort of non-Veterans Administration Medical

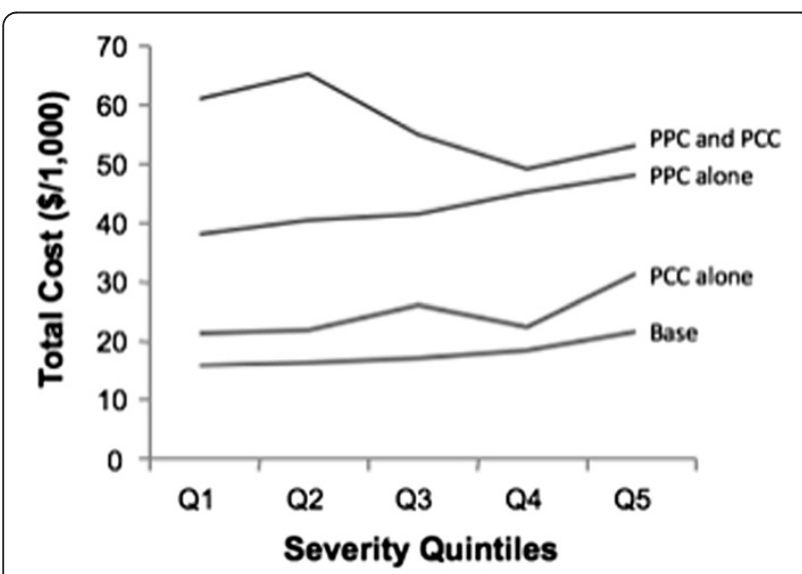

Figure 3 Base and incremental costs for postoperative complication groups by preoperative severity groups.
Centers, and they may actually have a better failure-torescue rate.

We observed that postoperative cardiac complications continue to occur at low rates $(2.9 \%$ overall incidence with $1.2 \%$ incidence of AMI) but are associated with a high mortality rate. This is consistent with other studies. For example, Dimick and colleagues at the University of Michigan found the incidence of 30-day cardiovascular complications to be $1 \%$ overall in a cohort of general and vascular surgery patients [9]. A 26.6\% in-hospital mortality is consistent with most contemporary studies and suggests that while decreasing in frequency, cardiac complications still carry a significant mortality. When evaluating the mortality rate for either complication, it is important to isolate solitary complications from those that are combined.

PPC was associated with a significant increased length of stay and overall costs. Dimick and colleagues demonstrated a $\$ 62,704$ average increment in costs in those patients with PPC in a mixed cohort of patients [9]. Khan and colleagues reported an increased hospital length of stay of $89 \%$ and increased costs by $55 \%$, which is more consistent with our findings [10]. Thompson and colleagues studied abdominal surgical patients and demonstrated an increased hospital length of stay of 11 days and charges of $\$ 31,000$ associated with PPC [11]. Short and colleagues utilized Medicare claims for the years 2005 through 2009 in six cancer resections and assessed the rate of complications using the Agency for Healthcare Research and Quality Patient Safety Indicators (PSI) [12]. They found that the rate of postoperative respiratory failure was $2.58 \%$ and increased costs by $>50 \%$ for all cancer resections. Vaughan-Sarrazin and colleagues looked at cost of complications in general surgery patients in the Veterans Administration NSQIP as a means of building a business case for improving surgical quality [13]. The average cost for patients with no complication was $\$ 22,000$, while the total costs for patients with a pulmonary embolism was $\$ 62,726$ and increased to more than $\$ 115,000$ for patients with failure to wean from the ventilator within $48 \mathrm{~h}$ of operation.

The significant medical and economic burden of postoperative pulmonary or cardiopulmonary complications clearly suggest that increased attention should be directed at reducing this complication. We included an analysis of cardiac complications in order to assess the importance of pulmonary complications in perspective. The past decade has seen numerous studies published which have evaluated interventions to reduce cardiac complications of noncardiac surgery [3]. Similar studies are lacking in the area of reducing the incidence and burden of pulmonary complications. Shander and colleagues have recently reported on a patient safety summit dedicated to risk-reducing and preventive strategies [4]. They have emphasized the paucity of data regarding 
such strategies as well as discussed potential technologies and strategies to reduce the incidence of ventilatorassociated pneumonia.

Our study has several limitations related to the use of administrative claims to assess burden and costs of disease. By using the Premier database, we have the distinct advantage of daily resource utilization and an enriched set of diagnostic codes. However, we still have the inherent limitation of any such dataset with regard to the accuracy of the codes and inclusions of all potentially relevant variables. For example, we did not analyze smoking status given the inaccuracy of this variable in discharge data. With respect to outcome measures, hospitals may have different definitions of the individual outcomes and surveillance for such outcomes. We also made some assumptions regarding the sequence of cardiac versus respiratory complications that could influence our findings.

\section{Conclusions}

We have demonstrated that postoperative pulmonary complications, either in isolation or in tandem with postoperative cardiac complications, occur at a high incidence after intestinal surgery and are associated with significant mortality and costs. Therefore, strategies to reduce the incidence of these complications should be targeted as means of improving health and bending the cost curve in health care.

\section{Competing interests}

Dr. Linde-Zwirble received funding to purchase the Premier database and consulting fees to demonstrate the value of the database from Covidien, which manufactures products which could be used to reduce perioperative pulmonary complications. The Department of Anesthesiology and Critical Care at the University of Pennsylvania has received grants and equipment from Covidien, but Dr. Fleisher has not received any direct research funds or honorarium.

\section{Authors' contributions}

LAF conceived of the study, participated in its design and analysis, and drafted the manuscript. WTLZ participated in the design of the study, performed the statistical analysis, and helped to draft the manuscript. Both authors read and approved the final manuscript.

\section{Acknowledgements}

The authors wish to acknowledge the assistance of Jonathan Bloom, M.D., and Doug Hansell, M.D., in the original concept of the study. Dr. Linde-Zwirble received funding from Covidien.

\section{Author details \\ 'Department of Anesthesiology and Critical Care, Perelman School of Medicine, Leonard Davis Institute of Health Economics, University of Pennsylvania, 3400 Spruce Street, Dulles 680, Philadelphia, PA 19104, USA. ${ }^{2}$ ZD Associates, Perkasie, PA, USA.}

Received: 10 June 2014 Accepted: 18 September 2014 Published: 7 October 2014

\section{References}

1. Finks JF, Osborne NH, Birkmeyer JD: Trends in hospital volume and operative mortality for high-risk surgery. N Engl J Med 2011 364:2128-2137.

2. Ghaferi AA, Birkmeyer JD, Dimick JB: Variation in hospital mortality associated with inpatient surgery. N Engl J Med 2009, 361:1368-1375.
3. Fleisher $L A$, Fleischmann KE, Auerbach AD, Barnason SA, Beckman JA, Bozkurt B, Davila-Roman VG, Gerhard-Herman MD, Holly TA, Kane GC, Marine JE, Nelson TM, Spencer CC, Thompson A, Ting HH, Uretsky BF, Wijeysundera DN: ACC/AHA guideline on perioperative cardiovascular evaluation and management of patients undergoing noncardiac surgery: a report of the American College of Cardiology/American Heart Association task force on practice guidelines. J Am Coll Cardiol 2014.

4. Shander A, Fleisher LA, Barie PS, Bigatello LM, Sladen RN, Watson CB: Clinical and economic burden of postoperative pulmonary complications: patient safety summit on definition, risk-reducing interventions, and preventive strategies. Crit Care Med 2011, 39:2163-2172.

5. Gupta H, Gupta PK, Fang X, Miller WJ, Cemaj S, Forse RA, Morrow LE: Development and validation of a risk calculator predicting postoperative respiratory failure. Chest 2011, 140:1207-1215.

6. Kennedy GD, Rajamanickam V, O'Connor ES, Loconte NK, Foley EF, Leverson $\mathrm{G}$, Heise CP: Optimizing surgical care of colon cancer in the older adult population. Ann Surg 2011, 253:508-514.

7. Arozullah AM, Khuri SF, Henderson WG, Daley J: Development and validation of a multifactorial risk index for predicting postoperative pneumonia after major noncardiac surgery. Ann Intern Med 2001, 135:847-857.

8. Jencks SF, Williams MV, Coleman EA: Rehospitalizations among patients in the Medicare fee-for-service program. N Engl J Med 2009, 360:1418-1428.

9. Dimick JB, Chen SL, Taheri PA, Henderson WG, Khuri SF, Campbell DA Jr: Hospital costs associated with surgical complications: a report from the private-sector National Surgical Quality Improvement Program. J Am Coll Surg 2004, 199:531-537.

10. Khan NA, Quan H, Bugar JM, Lemaire JB, Brant R, Ghali WA: Association of postoperative complications with hospital costs and length of stay in a tertiary care center. J Gen Intern Med 2006, 21:177-180.

11. Thompson DA, Makary MA, Dorman T, Pronovost PJ: Clinical and economic outcomes of hospital acquired pneumonia in intra-abdominal surgery patients. Ann Surg 2006, 243:547-552.

12. Short MN, Aloia TA, Ho V: The influence of complications on the costs of complex cancer surgery. Cancer 2014, 120:1035-1041.

13. Vaughan-Sarrazin M, Bayman L, Rosenthal G, Henderson W, Hendricks A Cullen JJ: The business case for the reduction of surgical complications in VA hospitals. Surgery 2011, 149:474-483.

doi:10.1186/2047-0525-3-7

Cite this article as: Fleisher and Linde-Zwirble: Incidence, outcome, and attributable resource use associated with pulmonary and cardiac complications after major small and large bowel procedures.

Perioperative Medicine 2014 3:7.

\section{Submit your next manuscript to BioMed Central and take full advantage of:}

- Convenient online submission

- Thorough peer review

- No space constraints or color figure charges

- Immediate publication on acceptance

- Inclusion in PubMed, CAS, Scopus and Google Scholar

- Research which is freely available for redistribution 